\section{Physiological Responses of Diverse Tall Fescue Cultivars to Drought Stress}

\author{
Bingru Huang ${ }^{1}$ and Hongwen $\mathbf{G a o}^{2}$ \\ Department of Horticulture, Forestry, and Recreation Resources, Kansas \\ State University, Manhattan, KS 66506-5506
}

Additional index words. drought tolerance, Festuca arundinacea, leaf water status, stomatal conductance, transpiration rate

\begin{abstract}
Drought is among the most limiting factors for turfgrass growth. Understanding genetic variations and physiological mechanisms in turfgrass drought resistance would facilitate breeding and management programs to improve drought resistance. The experiment was designed to investigate shoot physiological responses of six tall fescue (Festuca arundinacea Schreb.) cultivars representing several generations of turfgrass improvement to drought stress. Grasses were grown in well-watered or drying (nonirrigated) soil for 35 days in the greenhouse. Net photosynthetic rate $\left(P_{n}\right)$, stomatal conductance $\left(g_{s}\right)$, transpiration rate (Tr), relative water content (RWC), and photochemical efficiency ( $F v /$ Fm) declined during drought progression in all cultivars, but the time and the severity of reductions varied with cultivar and physiological factors. The values of $P_{n}, R W C, g_{s}$, and Tr decreased significantly for 'Rebel Jr', 'Bonsai', and 'Phoenix' when soil water content declined to $20 \%$ after 9 days of treatment (DOT) and for 'Houndog V', 'Kentucky-31', and 'Falcon II' when soil water content dropped to $10 \%$ at 15 DOT. A significant decrease in Fv/Fm was not observed in drought-stressed plants until 21 DOT for 'Rebel Jr', 'Bonsai', and 'Phoenix' and 28 DOT for 'Houndog V', 'Kentucky-31', and 'Falcon II'. The decline in $P_{n}$ resulted mainly from internal water deficit and stomatal closure under mild droughtstress conditions. After a prolonged period of drought stress (35 DOT), 'Falcon II', 'Houndog V', and 'Kentucky-31' maintained higher $P_{n}$ than did 'Rebel Jr', 'Bonsai', and 'Phoenix', which could be attributed to their higher Fv/Fm. This study demonstrated variation in drought resistance among tall fescue cultivars, which was related to their differential responses in photosynthetic capacity and water relations.
\end{abstract}

The popularity of tall fescue as a turfgrass has increased with the introduction of improved cultivars. This is partly due to its good drought resistance (Beard, 1989), as water resources are becoming increasingly limited. This species is better able to avoid drought than are other cool-season turfgrasses, such as perennial ryegrass (Lolium perenne L.) or Kentucky bluegrass (Poapratensis L.) (Sheffer et al., 1987). This difference has been attributed to tall fescue's physiological characteristics and its deep, extensive root system (Beard, 1989; Qian and Fry, 1997; Younger et al., 1981).

Within the tall fescue species, cultivars vary in drought resistance (Carrow, 1996; Huang et al., 1998; Huang and Fry, 1998; White etal., 1992, 1993). Carrow (1996) found that 'Bonsai', a dwarf-type tall fescue, had an inferior visual quality and more severe leaf

Received for publication 17 Aug. 1998. Accepted for publication 19 Feb. 1999. Contribution 99-41-J from the Kansas Agricultural Experiment Station. We thank Drs. Mary Beth Kirkham and Jack Fry for their helpful comments on the manuscript. This research was supported by the Kansas Agricultural Experiment Station and Kansas Turfgrass Foundation. The cost of publishing this paper was defrayed in part by the payment of page charges. Under postal regulations, this paper therefore must be hereby marked advertisement solely to indicate this fact. ${ }^{1}$ Assistant Professor.

${ }^{2}$ Visiting Scientist. Current address: Shanxi Academy of Agricultural Science, Taiyuan, Shanxi 030031, People's Republic of China.

HortScience, Vol. 34(5), August 1999 cultivars in response to drought stress; and 2) investigate the relative importance of water relations, stomatal conductance, and photochemical efficiency in contributing to maintenance of photosynthetic capacity in tall fescue cultivars under drought conditions.

\section{Materials and Methods}

Six tall fescue cultivars were examined in this study. 'Kentucky-31' is a forage type; 'Houndog V', 'Phoenix', and 'Falcon II' are turf types; and 'Rebel Jr' and 'Bonsai' are dwarf turf types. Sod pieces $(15 \mathrm{~cm}$ in diameter and $3 \mathrm{~cm}$ deep) of the six cultivars were collected from 5-year-old plots at the Rocky Ford Turfgrass Research Center, Kansas State Univ., Manhattan. Sod pieces were scraped and washed free of soil before planting in 15$\mathrm{cm}$-diameter $\times 60$-cm-deep polyvinylchloride (PVC) tubes filled with a mixture of 1 coarse river sand : 2 top soil (fine, montmorillonitic, mesic, Aquic, Arquidolls) (by volume) collected from the field.

Plants were grown from Feb. to May 1998 in a greenhouse with daily temperatures of 24 ${ }^{\circ} \mathrm{C}$ maximum $/ 15^{\circ} \mathrm{C}$ minimum and a photoperiod of $14 \mathrm{~h}$. The light regime in the greenhouse was supplemented with $1-\mathrm{kW}$ metal halide lamps placed $1.5 \mathrm{~m}$ above the turf canopy. Photosynthetically active radiation $(P A R)$ on a horizontal plane just above the canopy at noon averaged $800 \mu \mathrm{mol} \cdot \mathrm{m}^{-2} \cdot \mathrm{s}^{-1}$ during the experimental period. Plants were watered twice weekly to bring soil to near field capacity for 2 months before the drying treatment began. Controlled-release fertilizer $(17 \mathrm{~N}-$ $6 \mathrm{P}-10 \mathrm{~K})$ was topdressed twice prior to drydown to provide a total of $17 \mathrm{~g} \cdot \mathrm{m}^{-2} \mathrm{~N}$. Turf was hand-clipped twice weekly at a 6 -cm height.

The experiment consisted of two soil moisture treatments: a) well-watered control (plants were irrigated every other day until drainage occurred) and b) drought stress (irrigation was withheld and soil was allowed to dry for $35 \mathrm{~d}$ ). Volumetric soil water content in 0-20 and 40$60 \mathrm{~cm}$ soil layers was measured daily using time-domain reflectometry (TDR) (Topp et al., 1980). A set of three-pronged waveguides made of stainless steel, $20 \mathrm{~cm}$ long and $3.0 \mathrm{~mm}$ in diameter, were buried vertically $20 \mathrm{~cm}$ in each soil layer. Trase TDR (Soil Moisture Equipment, Santa Barbara, Calif.) provided a digital readout of soil volumetric water content (SWC). The field capacity of the soil medium is $30 \% \pm 2 \%$ (mean of four replications $\pm \mathrm{SE}$ ), which was measured in four PVC tubes with TDR when drainage ceased following watering the soil to complete saturation. Soil water content in the $0-$ to $60-\mathrm{cm}$ soil profile averaged $28 \%$ (93\% of FC) over the experimental period under well-watered conditions. Soil water content in the dry-down treatment declined to $\approx 20 \%$ ( $67 \%$ of FC) by 7 d, $10 \%$ (33\% of FC) by $14 \mathrm{~d}$, and 5\% (17\% of FC) by $18 \mathrm{~d}$ and remained at this level during the remainder of the drying period.

Several shoot characteristics, including net photosynthetic rate $\left(\mathrm{P}_{\mathrm{n}}\right)$, stomatal conductance $\left(g_{s}\right)$, transpiration rate $(\mathrm{Tr})$, leaf relative water content (RWC), and leaf photochemical effi- 
ciency as estimated by chlorophyll fluorescence ( $\mathrm{Fv} / \mathrm{Fm}$ ratio) were determined at various times after dry-down. All measurements were made on six young, fully expanded leaves from different plants in each PVC tube. The $\mathrm{P}_{\mathrm{n}}$, $g_{s}$, and $\mathrm{Tr}$ were measured with a LiCor 6400 (LI-COR, Lincoln, Nebr.) at a PAR of 1000 $\mu \mathrm{mol} \cdot \mathrm{m}^{-2} \cdot \mathrm{s}^{-1}$ and a chamber temperature of 22 ${ }^{\circ} \mathrm{C}$ from 1000 to $1300 \mathrm{HR}$ at each measurement time. The variable fluorescence/maximal fluorescence $(\mathrm{Fv} / \mathrm{Fm})$ ratio was determined with a plant efficiency analyzer (Hansatech Instrument Ltd., Kings Lynn, England). Leaf RWC was calculated based on leaf fresh weight, dry weight, and turgid weight measured after soaking leaves in water overnight.

The experiment involved two factors (six cultivars and two soil moisture treatments) with four replications arranged in a completely randomized design. Treatments were replicated four times in space. Treatment effects were determined by analysis of variance according to the general linear models procedure of the Statistical Analysis System (SAS Institute, Cary, N.C.). Variation was partitioned into cultivar and soil moisture as main effects and their corresponding interactions. The comparison of moisture treatments within a cultivar clearly showed performance of each cultivar under stress conditions. Thus, the emphasis was on comparing soil moisture treatment responses within a cultivar. Differences among soil moisture treatment means within each cultivar were separated by a protected least significant difference (LSD, $P \leq 0.05$ ) test and the LSD values are illustrated in the figures. Cultivars were also compared under soil drying conditions. The LSD values for cultivar comparisons are presented in the figure legends.

\section{Results}

Photosynthesis $\left(P_{n}\right)$. Leaf $\mathrm{P}_{\mathrm{n}}$ declined with soil drying beginning at $9 \mathrm{~d}$ of treatment (DOT) for 'Rebel Jr', 'Bonsai', and 'Phoenix' and at 15 DOT for 'Houndog V', 'Kentucky-31', and 'Falcon II' (Fig. 1). Averaged over the remainder of the drying period, $\mathrm{P}_{\mathrm{n}}$ of drought-stressed plants was reduced by $62 \%$ for 'Rebel Jr', $52 \%$ for 'Bonsai', 48\% for 'Phoenix', 40\% for 'Houndog V', 37\% for 'Kentucky-31', and $29 \%$ for 'Falcon II', relative to their respective well-watered controls. At 1 and 4 DOT, all cultivars had similar $P_{n}$, but that of 'Kentucky31' was the lowest (Table 1). At 9, 15, and 21 DOT, 'Falcon II' had a significantly higher $\mathrm{P}_{\mathrm{n}}$ than did 'Rebel Jr' and 'Bonsai'. By 28 DOT, $\mathrm{P}_{\mathrm{n}}$ of 'Falcon II' was significantly higher than that of all other cultivars, and the values for $\mathrm{P}_{\mathrm{n}}$ of 'Houndog V' and 'Kentucky-31' were higher than those for 'Rebel Jr' and 'Bonsai'.

Transpiration rate $(\mathrm{Tr})$ and stomatal conductance $\left(g_{s}\right)$. Transpiration rate $(\mathrm{Tr})$ was reduced by soil drying beginning at 4 DOT for 'Rebel Jr'; 9 DOT for 'Bonsai', 'Phoenix', and 'Houndog V'; and 15 DOT for 'Kentucky-31' and 'Falcon II' (Fig. 2). During the remainder of the drying period, Tr declined by $65 \%$ for 'Rebel Jr', 61\% for 'Bonsai', 53\% for 'Phoenix', $44 \%$ for 'Houndog V', $53 \%$ for 'Ken-

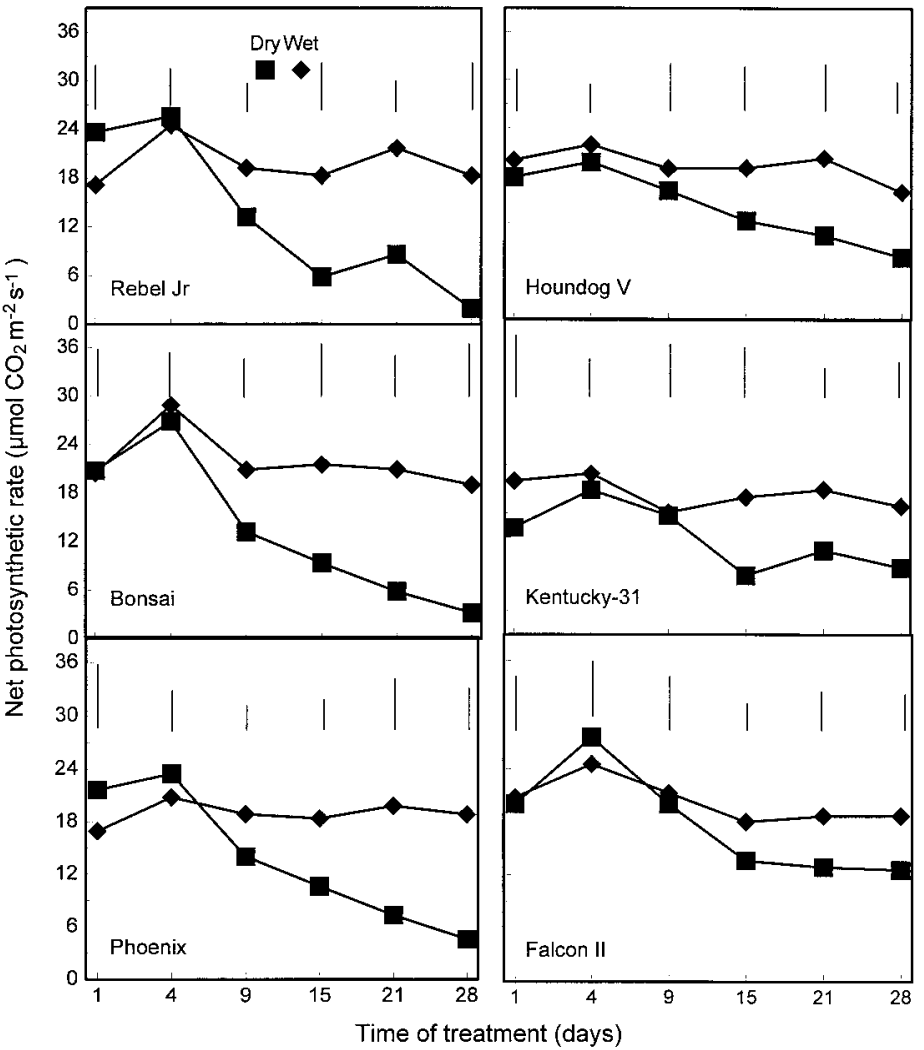

Fig. 1. Net photosynthetic rate $\left(\mathrm{P}_{\mathrm{n}}\right)$ in six tall fescue cultivars as affected by soil drying. Bars indicate LSD values for treatment comparisons within a given day of treatment for each cultivar $(P \leq 0.05)$.

Table 1. Comparisons of physiological parameters of tall fescue cultivars under soil drying conditions.

\begin{tabular}{|c|c|c|c|c|c|c|c|}
\hline \multirow[b]{2}{*}{ Cultivar } & \multicolumn{7}{|c|}{ Days of drying } \\
\hline & 1 & 4 & 9 & 15 & 21 & 28 & 35 \\
\hline & \multicolumn{7}{|c|}{$P_{n}$} \\
\hline Rebel Jr & $a^{2}$ & $\mathrm{a}$ & $\mathrm{b}$ & $c^{n}$ & $\mathrm{~b}$ & c & --- \\
\hline Bonsai & $\mathrm{a}$ & a & $\mathrm{b}$ & $\mathrm{b}$ & $\mathrm{b}$ & $\mathrm{c}$ & --- \\
\hline Phoenix & $\mathrm{a}$ & $a b$ & $a b$ & $a b$ & $\mathrm{~b}$ & $\mathrm{bc}$ & --- \\
\hline Houndog V & $a b$ & $a b$ & $a b$ & $a b$ & $a b$ & $\mathrm{~b}$ & --- \\
\hline K-31 & $\mathrm{b}$ & $\mathrm{b}$ & $a b$ & $\mathrm{bc}$ & $a b$ & b & --- \\
\hline \multirow[t]{2}{*}{ Falcon II } & $\mathrm{a}$ & a & a & $\mathrm{a}$ & $\mathrm{a}$ & $\mathrm{a}$ & --- \\
\hline & \multicolumn{7}{|c|}{$g_{s}$} \\
\hline Rebel Jr & $\mathrm{a}$ & $\mathrm{c}$ & $\mathrm{c}$ & $\mathrm{c}$ & $\mathrm{a}$ & $\mathrm{a}$ & --- \\
\hline Bonsai & $\mathrm{a}$ & $\mathrm{a}$ & $\mathrm{a}$ & $a b$ & $\mathrm{~b}$ & $\mathrm{a}$ & -- \\
\hline Phoenix & $\mathrm{a}$ & $\mathrm{b}$ & $\mathrm{b}$ & $\mathrm{b}$ & b & a & --- \\
\hline Houndog V & $\mathrm{a}$ & $a b$ & $a b$ & $\mathrm{a}$ & $\mathrm{a}$ & $\mathrm{a}$ & --- \\
\hline K-31 & $\mathrm{a}$ & $\mathrm{a}$ & $\mathrm{a}$ & $a b$ & $\mathrm{a}$ & $\mathrm{a}$ & --- \\
\hline \multirow[t]{2}{*}{ Falcon II } & $\mathrm{a}$ & $\mathrm{a}$ & $\mathrm{a}$ & $\mathrm{a}$ & $\mathrm{a}$ & $\mathrm{a}$ & --- \\
\hline & \multicolumn{7}{|c|}{$R W C$} \\
\hline Rebel Jr & $\mathrm{ab}$ & $\mathrm{b}$ & b & $\mathrm{c}$ & b & $\mathrm{b}$ & $\mathrm{b}$ \\
\hline Bonsai & $a b$ & b & b & $a b$ & b & b & b \\
\hline Phoenix & $\mathrm{a}$ & $\mathrm{a}$ & $\mathrm{a}$ & $\mathrm{b}$ & $a b$ & $a b$ & $\mathrm{a}$ \\
\hline Houndog V & $\mathrm{b}$ & $\mathrm{a}$ & $\mathrm{a}$ & $a b$ & $\mathrm{a}$ & $\mathrm{a}$ & $\mathrm{a}$ \\
\hline K-31 & $a b$ & $\mathrm{a}$ & b & $a b$ & $\mathrm{a}$ & a & $\mathrm{a}$ \\
\hline \multirow[t]{2}{*}{ Falcon II } & $a b$ & $\mathrm{a}$ & $\mathrm{a}$ & $\mathrm{a}$ & $\mathrm{a}$ & $\mathrm{a}$ & $\mathrm{a}$ \\
\hline & \multicolumn{7}{|c|}{$F v / F m$} \\
\hline Rebel Jr & $\mathrm{a}$ & $\mathrm{a}$ & $\mathrm{a}$ & $\mathrm{a}$ & $\mathrm{b}$ & $\mathrm{c}$ & $\mathrm{b}$ \\
\hline Bonsai & $\mathrm{a}$ & $\mathrm{a}$ & $\mathrm{a}$ & a & b & $\mathrm{b}$ & $\mathrm{b}$ \\
\hline Phoenix & $\mathrm{a}$ & $\mathrm{a}$ & $\mathrm{a}$ & $\mathrm{a}$ & $b$ & $\mathrm{~b}$ & $\mathrm{~b}$ \\
\hline Houndog V & $\mathrm{a}$ & $\mathrm{a}$ & a & $\mathrm{a}$ & $\mathrm{a}$ & $a b$ & $a b$ \\
\hline K-31 & $\mathrm{a}$ & $\mathrm{a}$ & $\mathrm{a}$ & $\mathrm{a}$ & $\mathrm{a}$ & $\mathrm{a}$ & $\mathrm{a}$ \\
\hline Falcon II & $\mathrm{a}$ & $\mathrm{a}$ & $\mathrm{a}$ & $\mathrm{a}$ & $\mathrm{a}$ & $\mathrm{a}$ & $\mathrm{a}$ \\
\hline
\end{tabular}

${ }^{2}$ Mean separation within columns and parameters by LSD $(P \leq 0.05) ; \mathrm{a}>\mathrm{b}>\mathrm{c}$. 
tucky-31', and $37 \%$ for 'Falcon II', relative to their respective controls. Stomatal conductance paralleled as transpiration rate (Fig. 3). At the initiation of drought stress (1 DOT), $g_{s}$ did not differ significantly among cultivars. At 4,9 , and 15 DOT, $g_{s}$ was significantly higher for 'Bonsai', 'Kentucky-31', and 'Falcon II' than for 'Rebel Jr' and 'Phoenix' (Table 1). By 28 DOT of drying, $g_{s}$ was reduced to low levels in all cultivars and did not differ significantly among cultivars. Cultivar variation in $\mathrm{Tr}$ in response to soil drying followed the same pattern as $g_{s}$ (Fig. 2).

Relative leaf water content ( $R W C$ ). During drying, RWC declined to a level below that of the well-watered controls starting at 4DOT for 'Rebel Jr' and 'Bonsai', and 9 DOT for 'Phoenix', 'Houndog V', 'Kentucky-31', and 'Falcon II' (Fig. 4). When RWC had decreased to $30 \%$ to $40 \%$, leaves became permanently wilted (without rehydration early in the morning), which occurred at 21 DOT for 'Rebel Jr', 'Bonsai', and 'Phoenix' and at 28 DOT for 'Houndog V', 'Kentucky-31', and 'Falcon II'. At 4, 9, 21, 28, and 25 DOT, 'Falcon II' and 'Houndog V' had higher RWC than did 'Rebel Jr' and 'Bonsai' (Table 1).

Leafphotochemical efficiency $(F v / F m)$. Soil drying did not reduce $\mathrm{Fv} / \mathrm{Fm}$ ratio significantly until 21 DOT for 'Rebel Jr', 'Bonsai', and 'Phoenix' and 28 DOT for 'Houndog V', 'Kentucky-31', and 'Falcon II' (Fig. 5). The Fv/Fm ratio did not differ significantly between cultivars before 15 DOT (Table 1). At 21, 28, and 35 DOT, 'Houndog V', 'Kentucky-31', and 'Falcon II' maintained significantly higher Fv/Fm ratios than did 'Rebel Jr', 'Bonsai', and 'Phoenix'.

\section{Discussion}

Previous research based on turf quality, leaf wilting, and rooting has suggested that dwarf turf-type cultivars of tall fescue have poorer drought resistance than turf-type or forage-type cultivars (Carrow, 1996; Huang and Fry, 1998; Huang et al., 1998; White et al., 1991, 1993). Various physiological responses $\left(\mathrm{P}_{\mathrm{n}}, \mathrm{Tr}, g_{s}, \mathrm{RWC}\right.$, and $\left.\mathrm{Fv} / \mathrm{Fm}\right)$ in the present study also indicated that drought resistance of dwarf turf-type cultivars Rebel Jr and Bonsai was inferior to that of the turf type ('Phoenix', 'Houndog V', and 'Falcon II') and forage type ('Kentucky-31'). 'Falcon II' appeared to be more drought resistant than 'Phoenix', but similar to 'Houndog V' and 'Kentucky-31', based on the responses of $\mathrm{P}_{\mathrm{n}}, g_{s}$, and Fv/Fm to prolonged periods of drought. Better performance and delayed leaf rolling of turf-type cultivars of tall fescue during drought stress have been attributed to low basal osmotic potential before stress, osmotic adjustment, prolonged turgor maintenance (White et al., 1992, 1993), and deep rooting (Carrow, 1996; Huang and Fry, 1998). Our study indicated that maintenance of photosynthetic activity and favorable transpiration during dry-down could be an important contributor to drought tolerance in tall fescue cultivars.

Reductions in photosynthesis generally are considered to be the result of reduced avail-

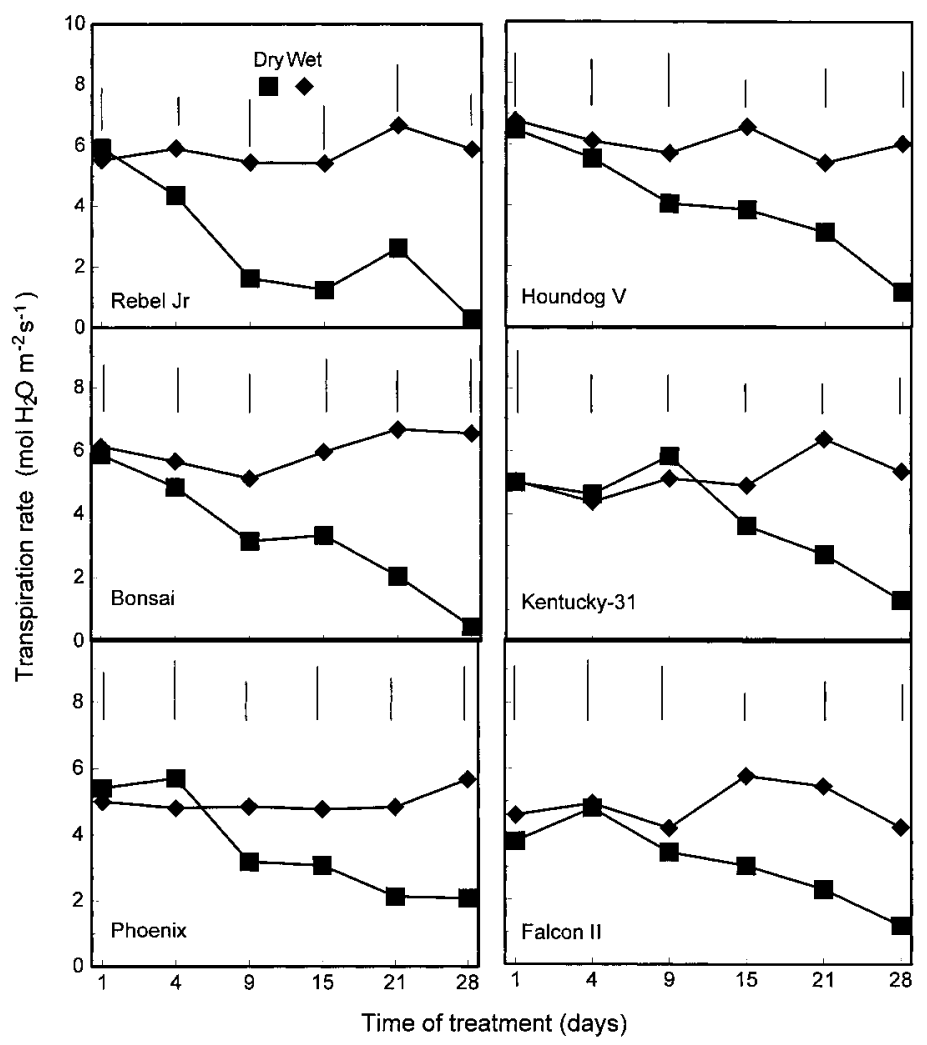

Fig. 2. Transpiration rate in six tall fescue cultivars as affected by soil drying. Bars indicate LSD values for treatment comparisons within a given day of treatment for each cultivar $(P \leq 0.05)$.

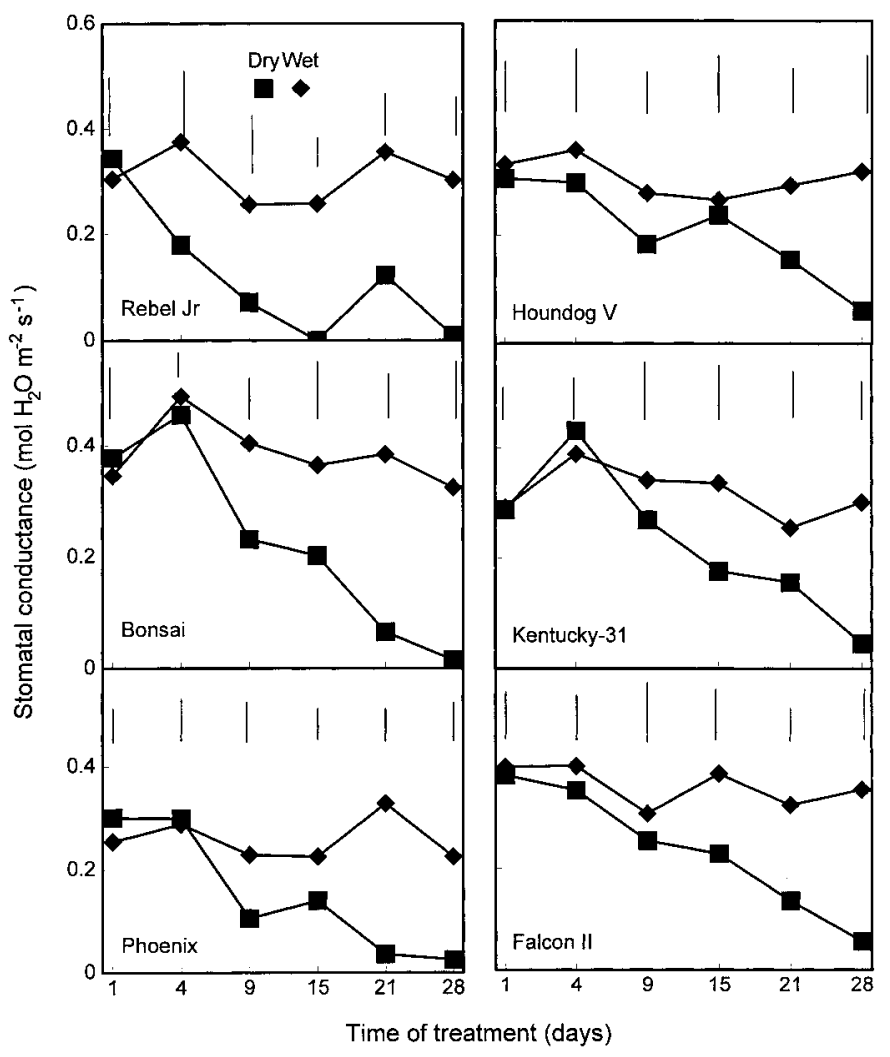

Fig. 3. Stomatal conductance $\left(g_{s}\right)$ in six tall fescue cultivars as affected by soil drying. Bars indicate LSD values for treatment comparisons within a given day of treatment for each cultivar $(P \leq 0.05)$. 


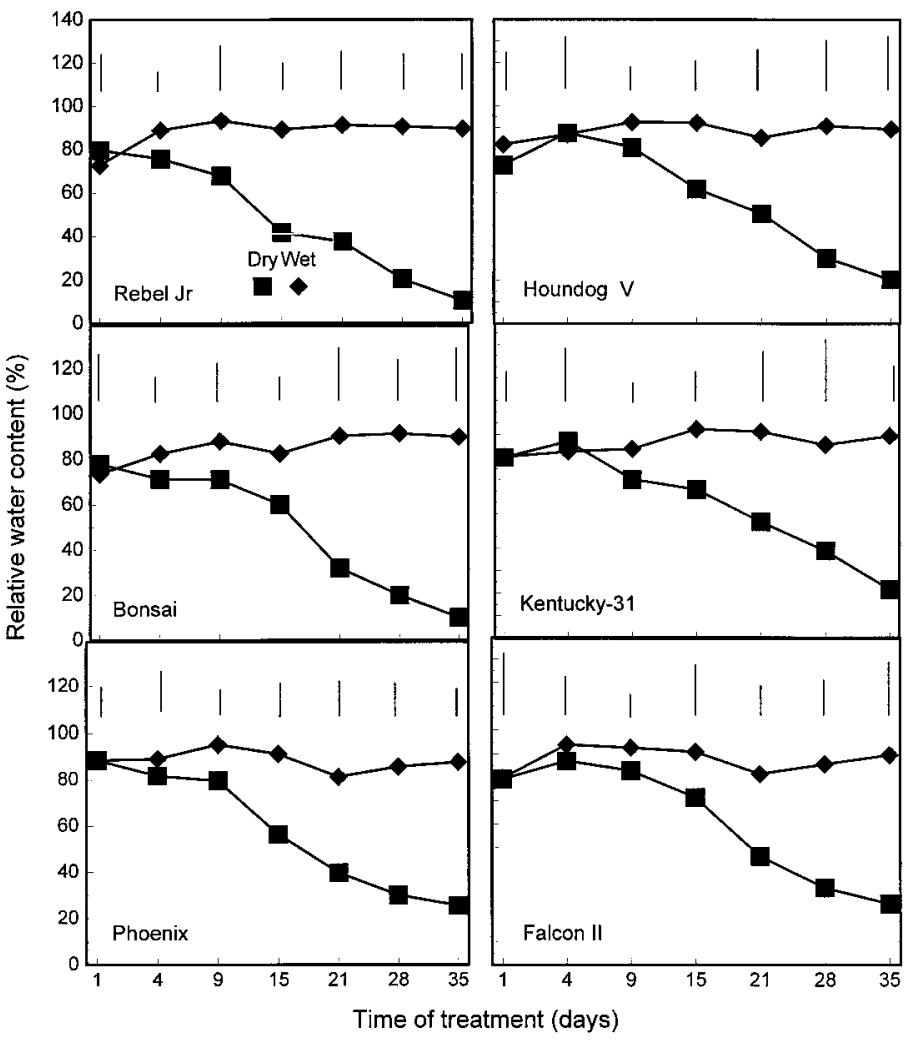

Fig. 4. Relative leaf water content (RWC) in six tall fescue cultivars as affected by soil drying. Bars indicate LSD values for treatment comparisons within a given day of treatment for each cultivar $(P \leq 0.05)$.

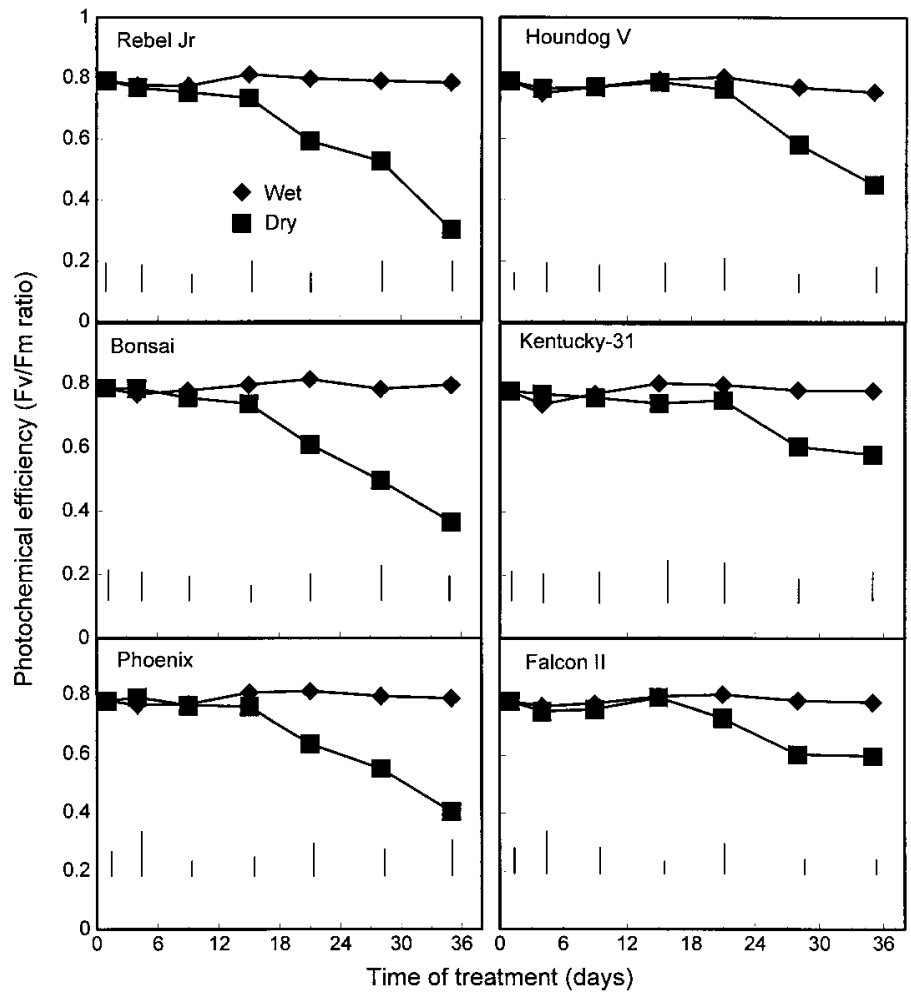

Fig. 5. Photochemical efficiency (Fv/Fm) in six tall fescue cultivars as affected by soil drying. Bars indicate LSD values for treatment comparisons within a given day of treatment for each cultivar $(P \leq 0.05)$ ability of $\mathrm{CO}_{2}$ because of stomatal closure (Kaiser, 1987; Schulze, 1986) or nonstomatal factors, such as photoinhibition or damage to chloroplast biochemistry or chlorophyll fluorescence (Baker, 1993; Krause and Weis, 1991). Chlorophyll fluorescence is proportional to the photochemical efficiency of leaves (Baker, 1993). In the present study, decline in $\mathrm{P}_{\mathrm{n}}$ occurred and was accompanied by partial stomatal closure, as indicated by the reduced $g_{s}$ and $\mathrm{Tr}$, when soil water content declined to $10 \%$ to $20 \%$ (33\% to $67 \%$ of FC) and RWC declined to $\approx 60 \%$. Photosynthetic rate was more sensitive to decline in soil moisture for 'Rebel Jr', 'Bonsai', and 'Phoenix' than for 'Houndog V', 'Kentucky-31', and 'Falcon II'. However, drought stress did not induce decreases in $\mathrm{Fv} / \mathrm{Fm}$ in any cultivar until RWC decreased to $30 \%$ to $40 \%$. The decline in $P_{n}$ in tall fescue cultivars appeared to be controlled mostly by stomatal closure under moderate drought-stress conditions.

When permanent leaf wilting occurred after a prolonged period of drought stress (35 DOT), the cultivars that maintained higher Fv/ Fm ratios ('Falcon II', 'Houndog V', and 'Kentucky-31') also had higher $\mathrm{P}_{\mathrm{n}}$ than did the other cultivars, although their $g_{s}$ and $\operatorname{Tr}$ values were not different. This suggests that maintenance of photosynthetic capacity under severe stress condition could be associated with less damage to the photosynthetic apparatus. In a previous study, Huang et al. (1998) reported that the Fv/Fm ratio was reversible when soil was rewet following a 14-d dry-down, but became irreversible following a 21-d dry-down, at which time soil moisture had declined $<10 \%$ and RWC was $<30 \%$ in 'Kentucky-31' and 'MIC18'. Kaiser (1987) reported that an irreversible decrease in photosynthetic capacity occurs as RWC drops $<30 \%$, leading to cell death from membrane damage in chloroplasts.

In summary, tall fescue cultivars, even within the same type, varied in water relations and photosynthetic responses to drought stress. Use of drought-resistant cultivars would reduce water use. The decline in $\mathrm{P}_{\mathrm{n}}$ during shortterm drought stress was due mostly to internal water deficit and stomatal closure. During a prolonged period of drought stress, high $\mathrm{P}_{\mathrm{n}}$ could be attributed to high photochemical efficiency. Photosynthetic rate, stomatal conductance, and transpiration rate could be used as drought stress indicators in selecting for drought resistance in tall fescue.

\section{Literature Cited}

Baker, N.R. 1993. Light-use efficiency and inhibition of photosynthesis in plants under environmental stress, p. 221-235. In: J.A.C. Smith and H. Griffiths (eds.). Water deficits-Plant responses from cell to community. Bios Scientific, Oxford, U.K.

Beard, J.B. 1989. Turfgrass water stress: Drought resistance components, physiological mechanisms, and species-genotype diversity, p. 23 28. In: H. Takatoh (ed.). Proc. 6th Intl. Turf. Sci. Soc., Jpn. Soc. Turf. Sci. Tokyo.

Bowman, D.C. and L. Macaulay. 1991. Comparative evapotranspiration rates of tall fescue cultivars. HortScience 26:122-123.

HortScience, Vol. 34(5), August 1999 
Carrow, R.N. 1996. Drought avoidance characteristics of diverse tall fescue cultivars. Crop Sci 36:371-377.

Huang, B. and J.D. Fry 1998. Root anatomical, morphological, and physiological responses to drought stress for tall fescue cultivars. Crop Sci. 38:1017-1022.

Huang, B., J.D. Fry, and B. Wang. 1998. Water relations and canopy characteristics of tall fescue cultivars during and after drought stress. HortScience 33:837-840.

Kaiser, W.M. 1987. Effects of water deficit on photosynthetic capacity. Physiol. Plant. 71:142149.

Kopec, D.M., R.C. Shearman, and T.P. Riordan 1988. Evapotranspiration of tall fescue turf
HortScience 23:300-301

Krause, G.H. and E. Weis. 1991. Chlorophyll fluorescence and photosynthesis: The basics. Annu. Rev. Plant Physiol. Plant Mol. Biol. 42:313349.

Qian, Y. and J.D. Fry. 1997. Rooting and drought avoidance of warm-season turfgrasses and tall fescue in Kansas. Crop Sci. 37:905-910.

Schulze, E.D. 1986. Carbon dioxide and water vapor exchange in response to drought in the atmosphere and the soil. Annu. Rev. Plant. Physiol. 37:247-274.

Sheffer, K.M., J.H. Dunn, and D.D. Minner. 1987. Summer drought responses and rooting depth of three cool-season turfgrasses. HortScience 22:296-297.
Topp, G.C., J.L. Davis, and A.P. Annan. 1980. Electromagnetic determination of soil water content: Measurements in coaxial transmission lines. Water Resource Res. 16:574-582.

White, R.H., A.H. Bruneau, and T.J. Cowett. 1993. Drought resistance of diverse tall fescue cultivars. Intl. Turf. Soc. Res. J. 7:607-613.

White, R.H., M.C. Engelke, S.J. Morton, and B.A. Ruemmele. 1992. Competitive turgor maintenance in tall fescue. Crop Sci. 32:251-256.

Younger, V.B., A.W. Marsh, R.A. Strohman, V.A Gibeault, and S. Spalding. 1981. Water use and quality of warm-season and cool-season turfgrasses, p. 257-259. In: R.W. Sheard (ed.). Proc. 4th Intl. Turf. Sci. Soc., Univ. of Guelph, Ont., Canada. 